نبـدأ هـذا العـدد مـن المجلة (1) عقدـاً جديـاً مـن عمرهـا المديـد إن شـاء الله، بعـد أن تمكنا بفضل الله سبحانه من إصدارها بصورة فصلية منتظمة (أربعة أعداد في السنة) منذ صيف عام ه9 99 (م. ويلاحظ القارئ الكريم أن مجموعة جديدة من العلماء قد انضموا إلى الهيئتين: الإدارية والاستشارية، يحملون معهم كفاءات وخبرات وتخصصـات متنوعة، ويتمتعون بمكانة علميـة وفكريـة مرموقة. وسوف يكـون لهم إسهامهم المقدّر في توجيه المجلـة ودعم رسـالتها وترشيد خطواتها. فخطاب الإصلاح والتجديد المنشود يقوم على التكامل المعرفي، ويربط ربطاً بنيوياً معارفنا في مجالات العلوم الاجتماعية والإنسانية بالوحي الإلهي والهدي النبوي؛ تحوئ تحقيقاً

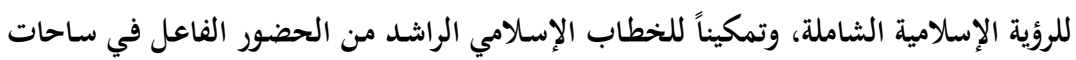
التدافع والتثاقف في العالم المعاصر.

\title{
نحو إعلام حضاري
}

هيئة التحرير

أصسبح الاتصـال والإعـلام في الواقـع المعاصـر شـأناً مهمــاً في حيـاة النـاس أفـراداً وبحتمعات. وتعددت مفاهيم الإعلام ووسائله وأساليبه ومضامينه، فلم يعد يملك الإنسان

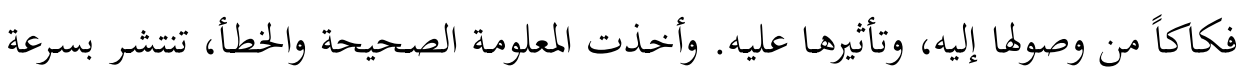

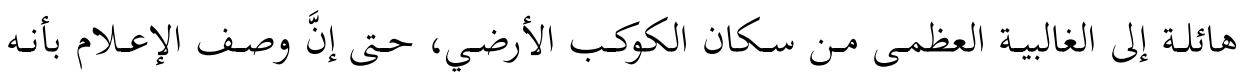

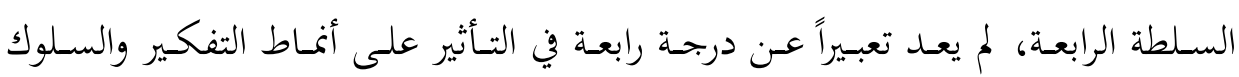

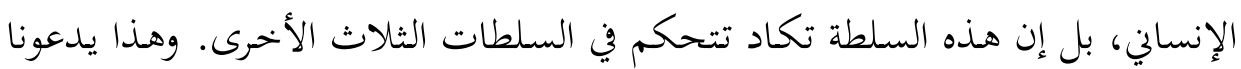
إلى وقفـة للتفكر والتـدبر في فهم الظـاهرة الإعلاميـة وآليـات عملها، ومحاولـة تشريكها،

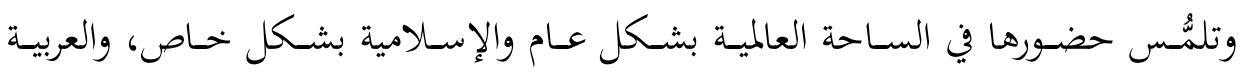
بصورة أكثر خصوصية. 


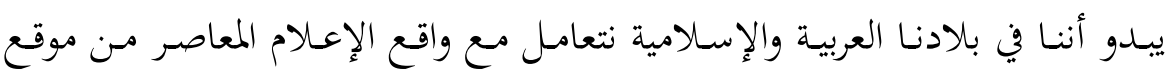

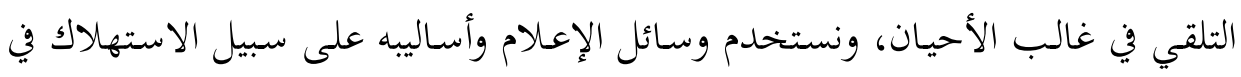

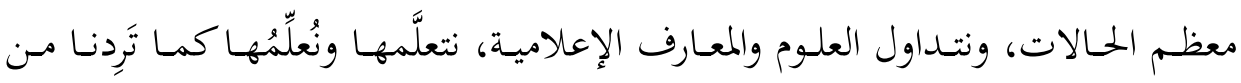

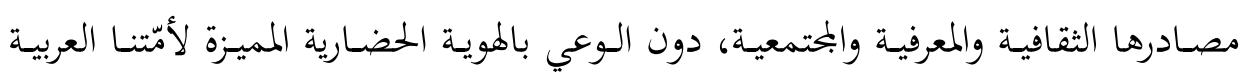

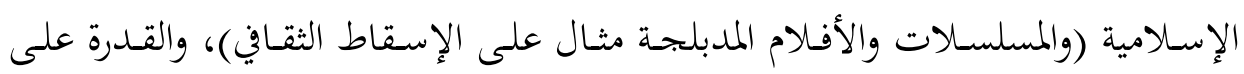

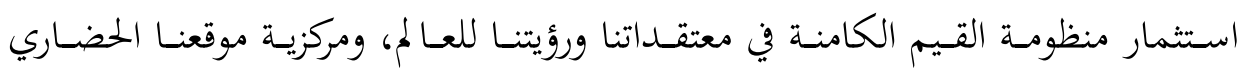

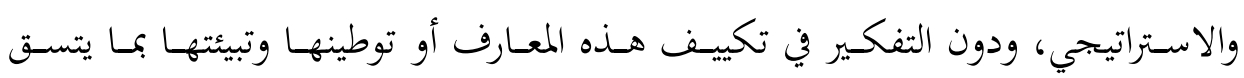
والثقافة العربية الإسلامية ونظامها المعرئ. ودولئ

ولعلَّه قد مضى ذلك الزمن الذي كان يمكن فيه تحديد مصادر الإعلام ووسائله التي

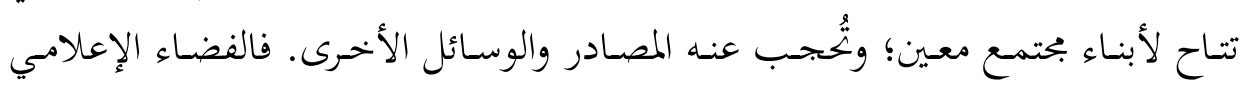

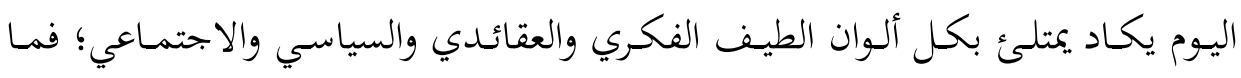

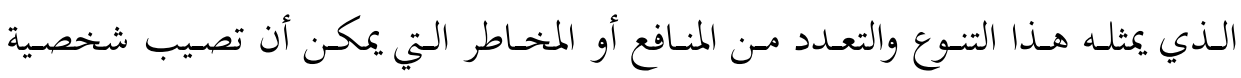
المواطن في بحتمعاتنا؟

وإذا كانت وسـائل الإعلام متاحة لكل فئات المحتمع العمرية، فمـا أثر هـذا التعـدد

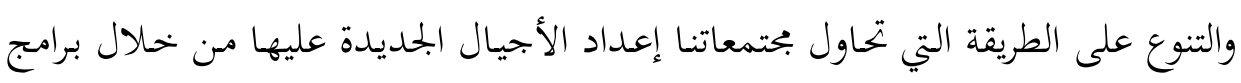

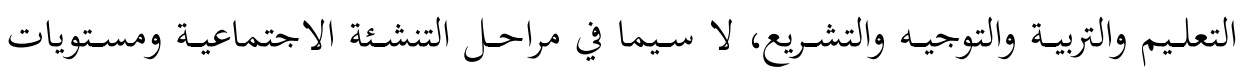

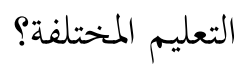

ولعل في هذا دعوة للعقل المسلم كي ينعم النظر في مدى القدرة على إعمال رؤيتنا

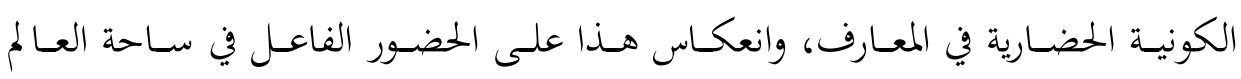
الإعلامي إنتاجاً وإصلاحاً وترشيداً.

من الملاحظ أنَّ التطور الذي حدث ولا يزال يحدث في وسائل الاتصال والإعلام،

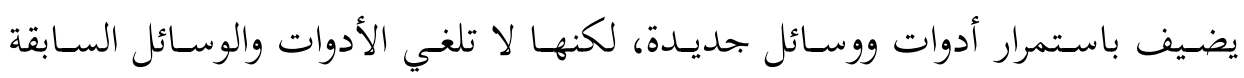

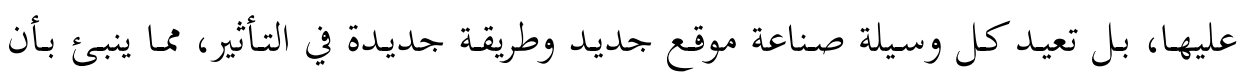

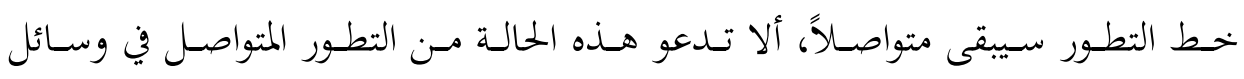


الاتصال والإعلام وأساليب تأثيرها، إلى القلق من الوقوف أمامها موقف المتفرج، دون أن

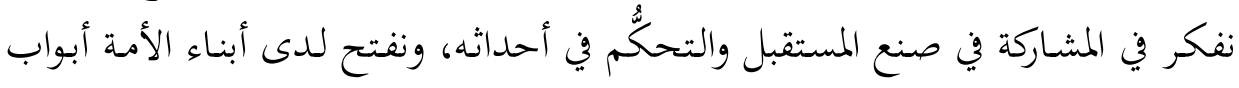

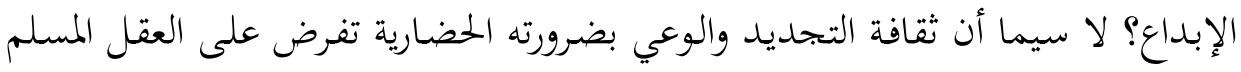

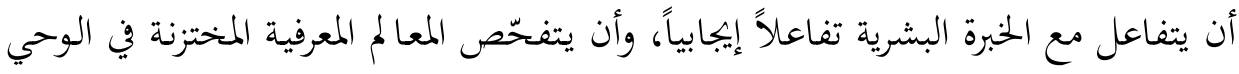

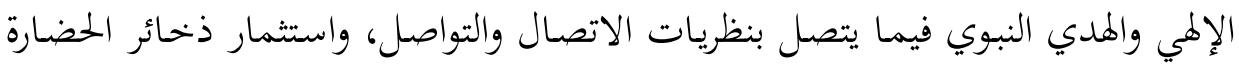

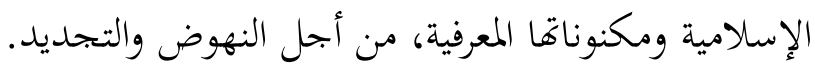

ولعل الحاجة إلى الإسهام الحضاري الإسلامي مُلحّة في هذا الوقت أكثر من غيره،

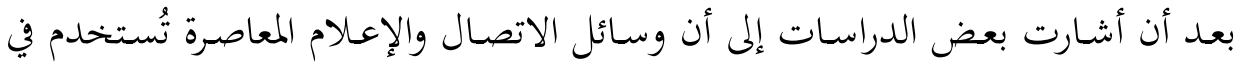

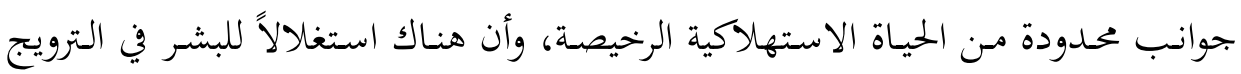

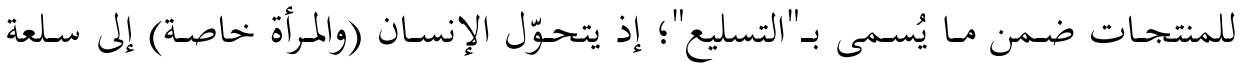

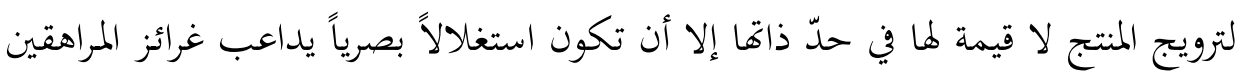

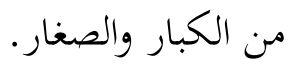

إنّ الآثار السلبية للإعلام المعاصر ليست قدراً لا يملك الإنسان أمامه إلا الاستسلام

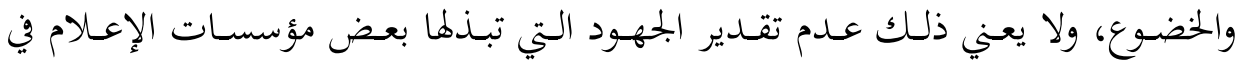

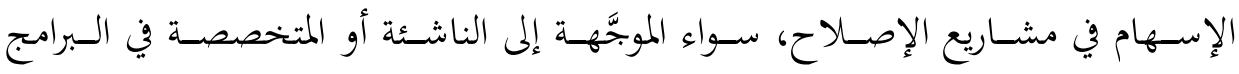

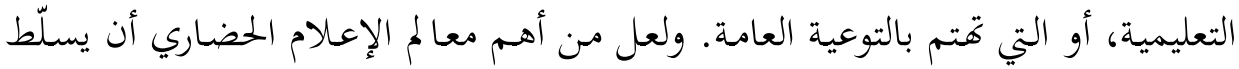

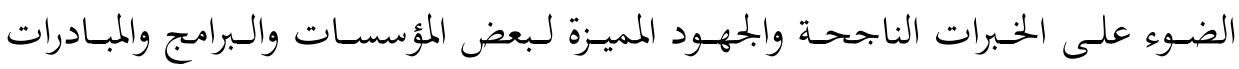

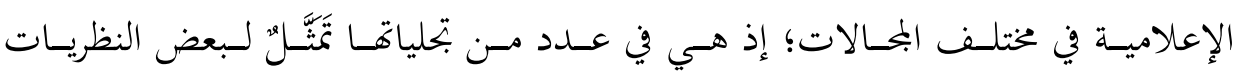

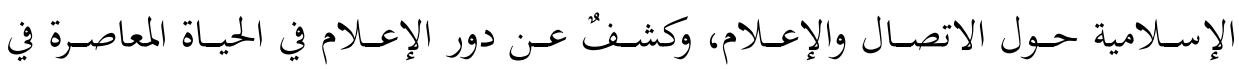

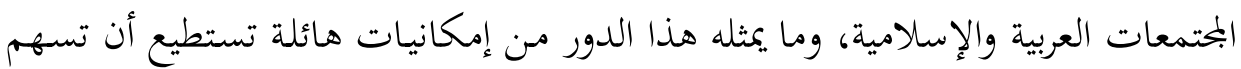

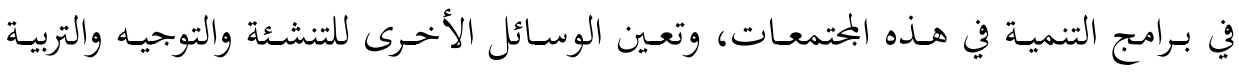

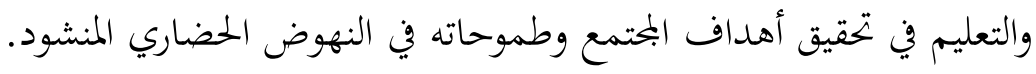

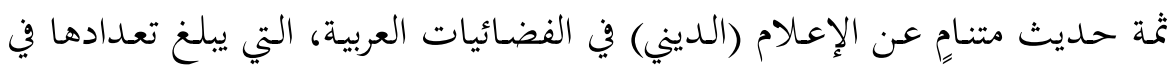

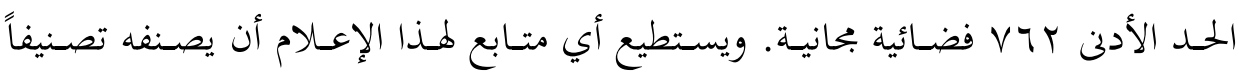


سريعاً حسب موضوعاته ومرجعاياته ومقاصده. فهناك إعلام (طائفي) يُعبّر عن توجهات

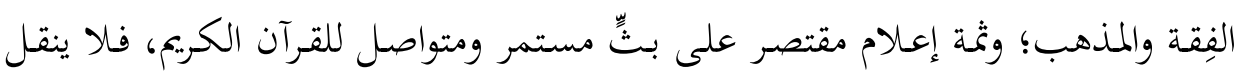

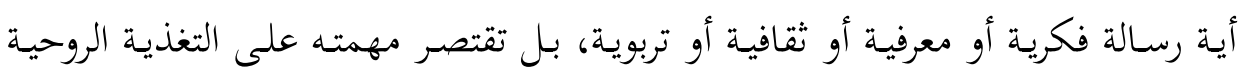

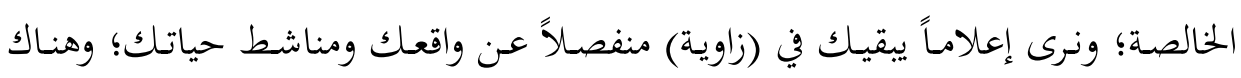

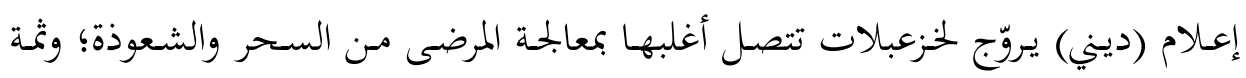

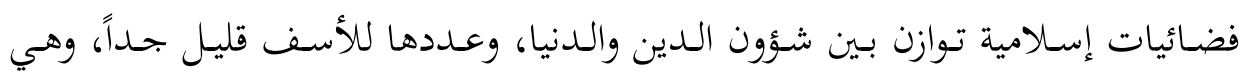

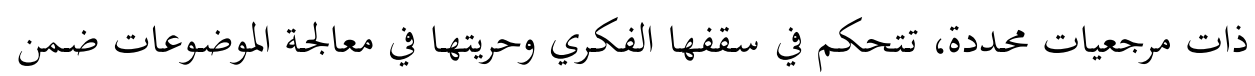
تلك المرجعيات الفكرية والمالية والإدارية.

وثمـة إعـام مخصص للأطفال، وهـو في أغلبـه ترفيهي يعتمـد على الأناشيد، ولكنهـ

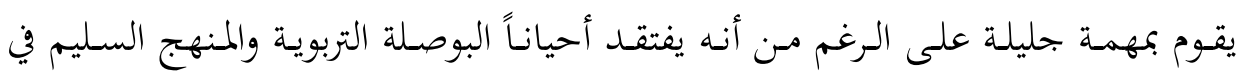

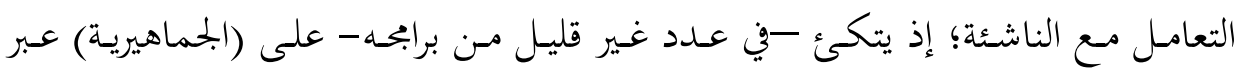
أناشيده، دون اعتبار للمضمون التربوي، الذي ربما يتعارض في بعض الأحيان مع الرؤية

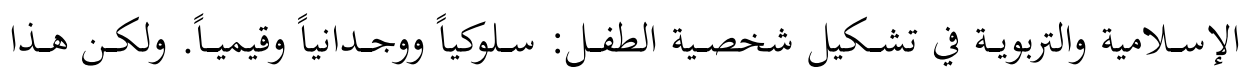
الإعلام يبقى نقطة مضيئة في سماء الإعلام (الديني)؛ إذ غطّى مساحة تتصل بالأسرة،

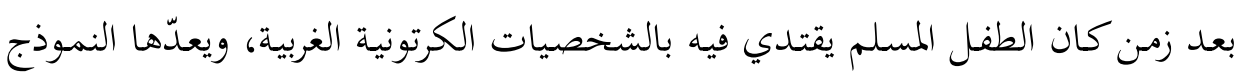
المثالي له في عالم اليوم والغد.

وثمة إعلام لا نتردد في وصفه بإعلام التفرقة والشحن بالبغضاء والكراهية، لإنه مغرق

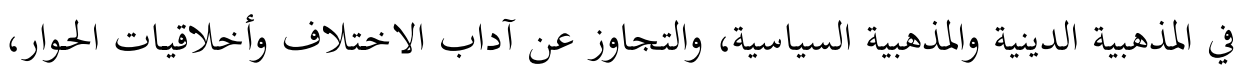

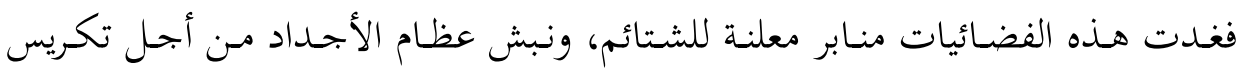

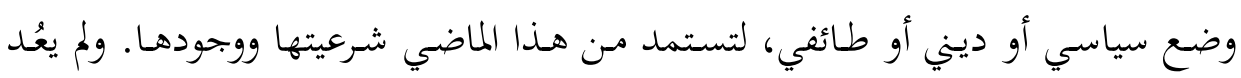

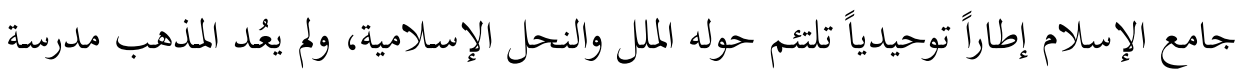

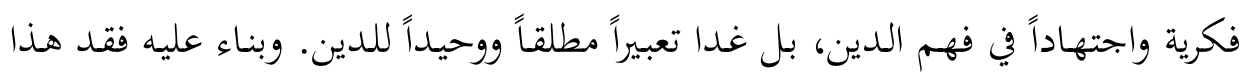
النوع من الإعلام (الديني) الصفات التي تؤهله لأداء رسالة في التنمية الفكرية والتجديد الفقهي والتماسك المجتمعي. 
إنَّ الحاجة ماسّة اليوم لرسم سياسة ثقافية إعلامية تمدف إلى تطوير خطاب إعلامي

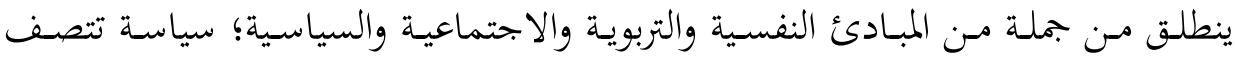

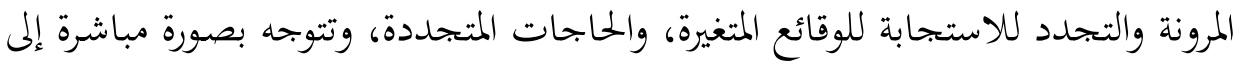

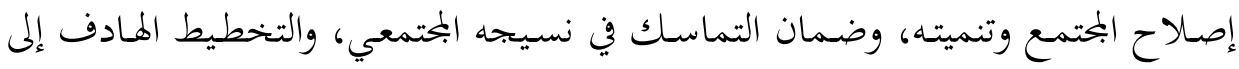

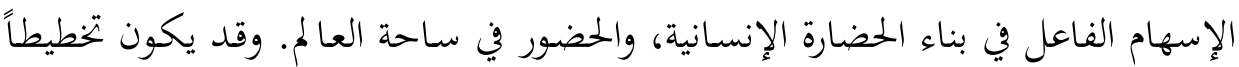
فكرياً ثقافياً لكنه يؤدي إلى إبحاز بحتمعي وإبداع حضاري. الإنساني، والحضور فيأ

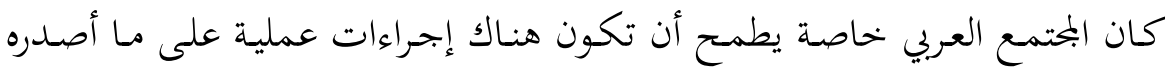

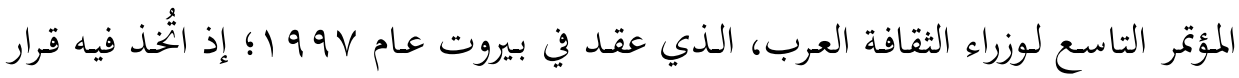

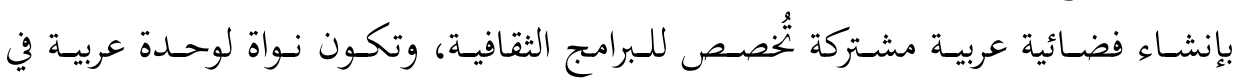

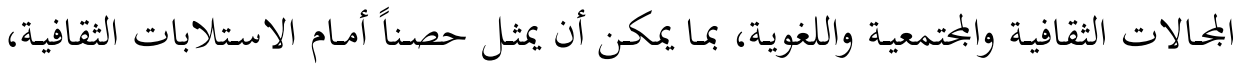

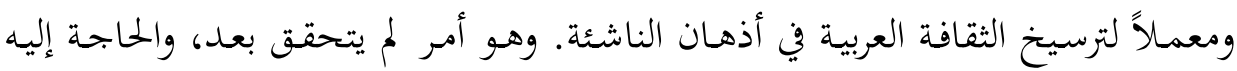

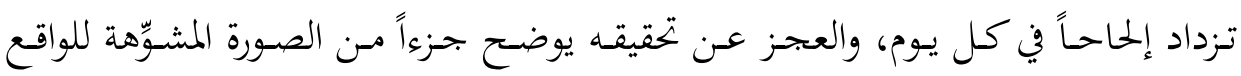

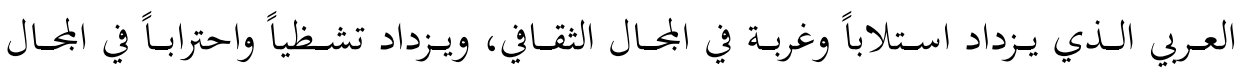

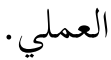

إن وعينا بأهمية الإعلام وجميع أشكال التواصل: المرئية والمسموعة والمقروءة في صياغة

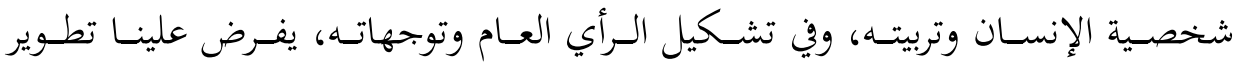

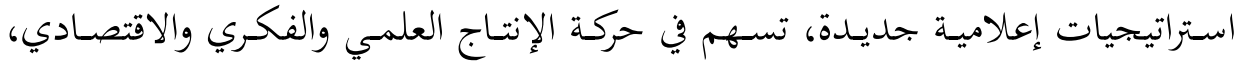

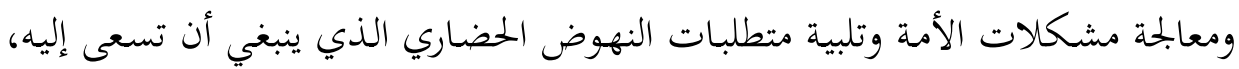

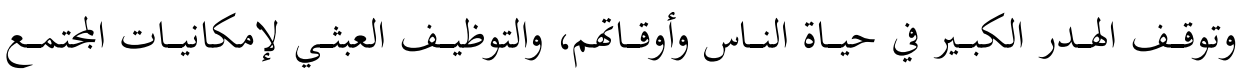

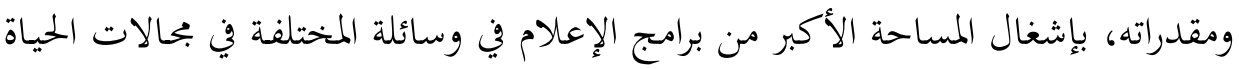
الاستهلاكية الرخيصة، وتكريس مظاهر الاستلاب والتبعية.

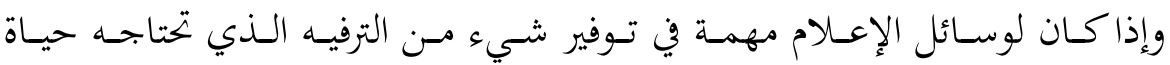

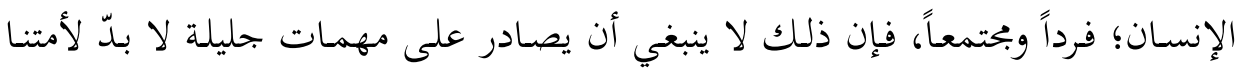

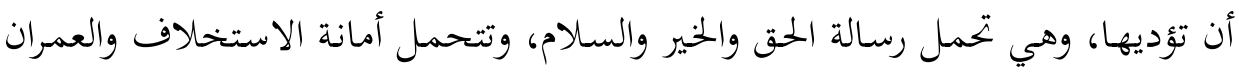


في الأرض. وبـلاً من أن يحمل الإعلام في البلاد العربية والإسلامية هذه الرسالة ويبشر

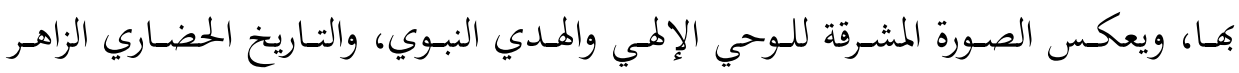

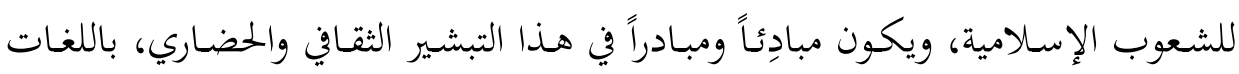

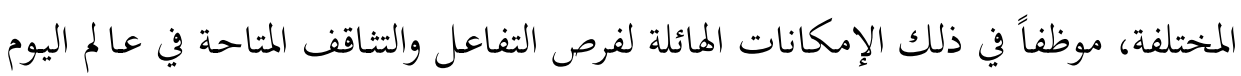

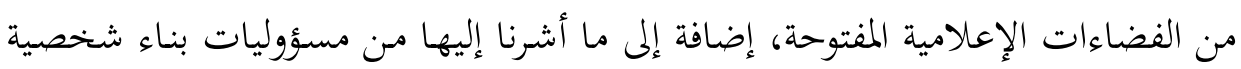

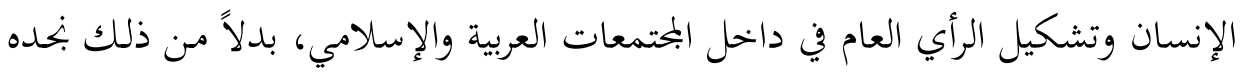

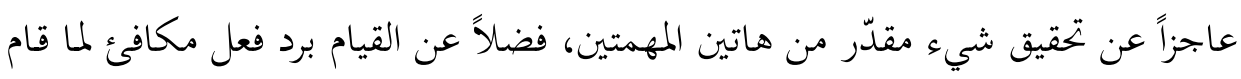

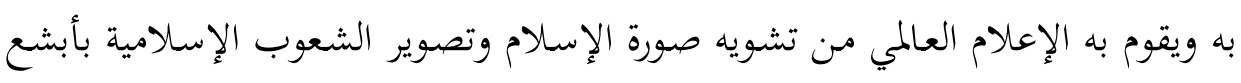
الصور.

وحسين نتحـدث عن رؤية إسـامية للإعلام المعاصر، فإن لا ينبغي أن ننسى ضرورة

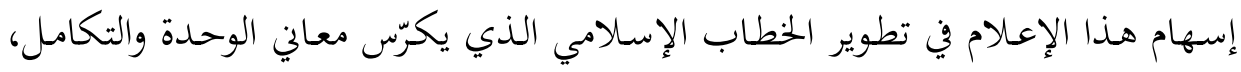

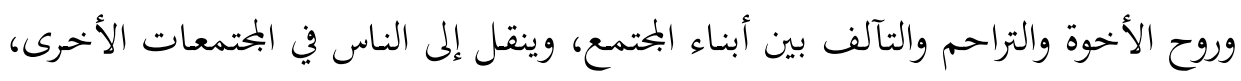

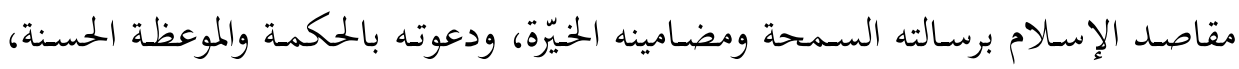

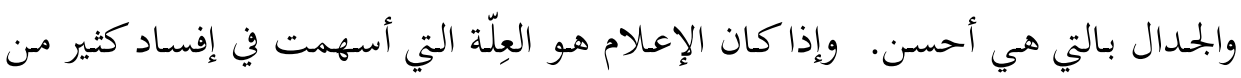

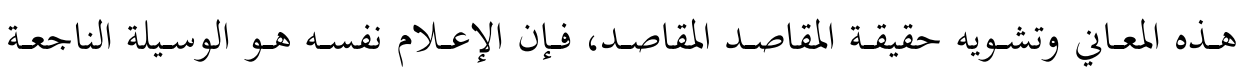
لمعالجة هذه العِلّة.

الخطـاب الإسـلامي الجحديـد الـذي على الإعـلام أن يحمله، سـوف ينقـل الرسـالة

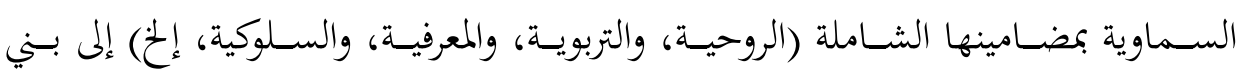

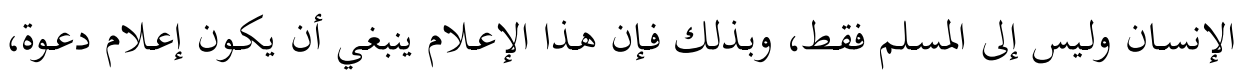

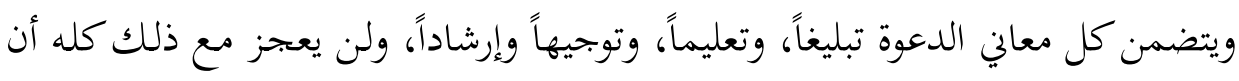
يقدم برامجه بصورة محببة ومريحة، لا تخلو من ترفيه نظيف، وترويح جميل. ولعل هذا ما ركز

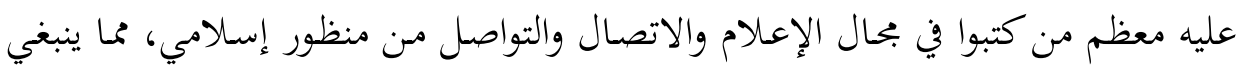

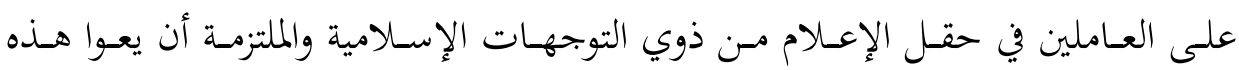


الحقيقة، لأها بمثابة مقياس، نستطيع من خلاله قياس مدى قرب البرامج أو ابتعادها عن منطلقات التصوّر الإسلامي ومقاصده وغاياته. في ظل التطورات والتحـولات الاجتماعيـة والسياسـية والثقافيـة ...، فُرضست على المجتمعـات جميعهـا أن تنشـئ أو تطوّر أو تبلـور منظومـة قـادرة على التعامـل مـع هـــهـ

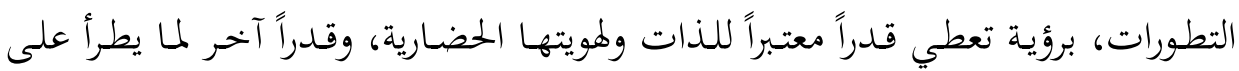

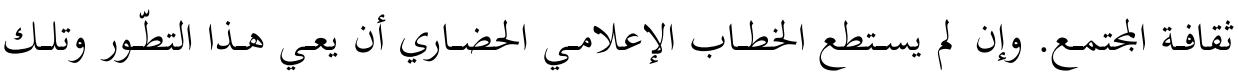
المستجدات فإنه سيسير في طريق بجهـول، لـه آثناره السـبية على بنـاء الذات وتشكيل

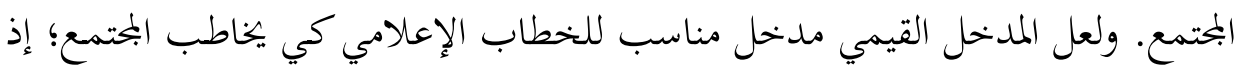
لا يختلف اثنان على أهمية القيم، وأن حضورها عاملهُ في استقرار حياة الفرد، وفي تماسك

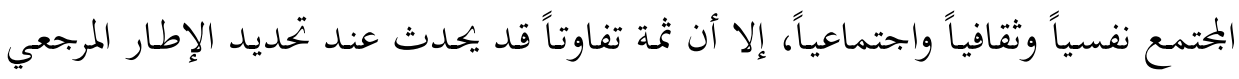
لهذه القيم، لا سيما في ظل الهيمنة الثقافية للغرب (المركز) على المنظومة الثقافية لبـاقي

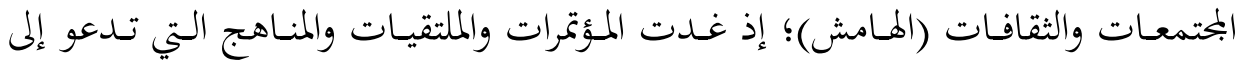
توحيد منظومة القيم وتنميطها لا تراعي خصوصيات الثقافات وهوياتها؛ انطلاقاً من أن

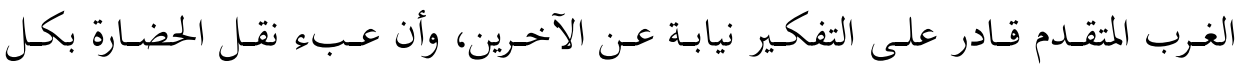
متعلقاتها منوط به. ويستطيع المراقب أن يلحظ الآن أن ثمة قرارات دولية تتعلق بالقيم،

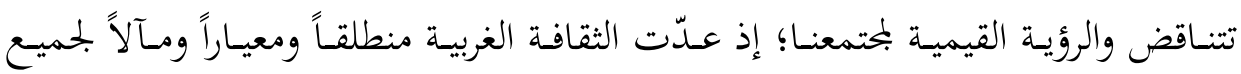
الثقافات، وغدت الثقافة الاستهلاكية المرتبطة بالأفلام والمناهج مِعْولاً لمدم معالمُ الثقافة

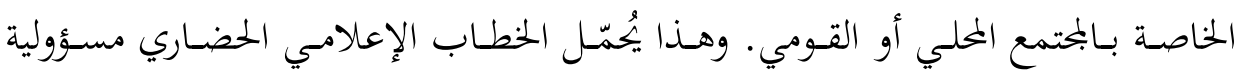
أخلاقيـة وأدبيـة في أن يكـون المنـافح عـن البُعـد القيمي للمجتمـع، والمـتبط بهويـة الأمـة ومرجعيتها؛ إذ إن الخطاب الإعلامي الحضاري، بما يتضمنه من مرجعية دينية، هو المؤهل لتحمل هذا العبء.

إن استثمار خطابنا الإعلامي للبُعد القيمي سيمكّنه من تنظيم البحتمع أخلاقياً؛ أي إدمــاج المفــاهيم الأخلاقيـة في الحيــاة العامـة: السياســية والاجتماعيـة والاقتصــادية

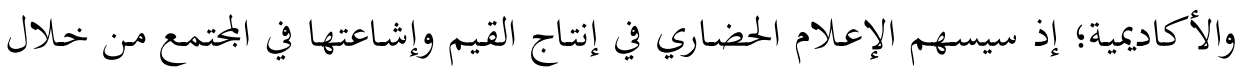


البرامج الثقافيـة؛ بجميع تمثلاتها، مما سيؤثر بعد ذلك في التنشئة الاجتماعيـة؛ فيتأسس الفرد على مبادئ وقيم نابعة من هوية المجتمع، فيصبح هذا الفعل مقابلاً منطقياً للتحللّ

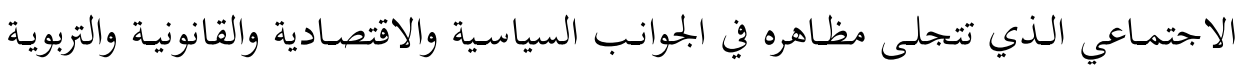
والثقافية.

يأتي هـذا العـدد مـن بحلة إسـلامية المعرفـة متضـمناً عـدداً مـن البحـوث النوعيـة التي

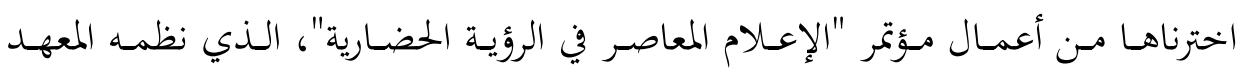

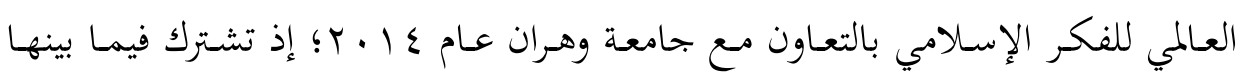

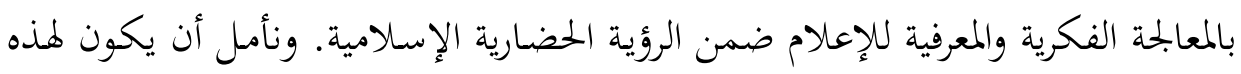

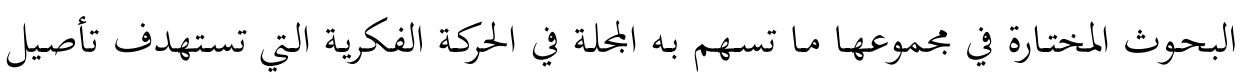

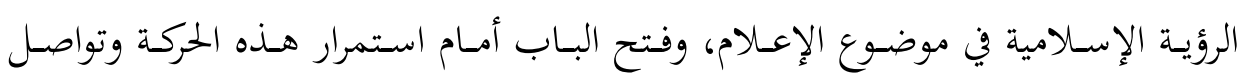
عطائها تطويراً وبكثاً وتأليفاً ونشراً. والله ولي التوفيق 